\title{
Identification of differentially expressed genes induced by Bamboo mosaic virus infection in Nicotiana benthamiana by CDNA-amplified fragment length polymorphism
}

\author{
Shun-Fang Cheng ${ }^{1}$, Ying-Ping Huang ${ }^{1}$, Zi-Rong Wu', Chung-Chi Hu' ${ }^{1}$ Yau-Heiu Hsu ${ }^{1,2}$, Ching-Hsiu Tsai ${ }^{1,2^{*}}$
}

\begin{abstract}
Background: The genes of plants can be up- or down-regulated during viral infection to influence the replication of viruses. Identification of these differentially expressed genes could shed light on the defense systems employed by plants and the mechanisms involved in the adaption of viruses to plant cells. Differential gene expression in Nicotiana benthamiana plants in response to infection with Bamboo mosaic virus (BaMV) was revealed using cDNA-amplified fragment length polymorphism (AFLP).

Results: Following inoculation with BaMV, N. benthamiana displayed differential gene expression in response to the infection. Isolation, cloning, and sequencing analysis using CDNA-AFLP furnished 90 cDNA fragments with eight pairs of selective primers. Fifteen randomly selected genes were used for a combined virus-induced gene silencing (VIGS) knockdown experiment, using BaMV infection to investigate the roles played by these genes during viral infection, specifically addressing the means by which these genes influence the accumulation of BaMV protein. Nine of the 15 genes showed either a positive or a negative influence on the accumulation of BaMV protein. Six knockdown plants showed an increase in the accumulation of BaMV, suggesting that they played a role in the resistance to viral infection, while three plants showed a reduction in coat protein, indicating a positive influence on the accumulation of BaMV in plants. An interesting observation was that eight of the nine plants showing an increase in BaMV coat protein were associated with cell rescue, defense, death, aging, signal transduction, and energy production.

Conclusions: This study reports an efficient and straightforward method for the identification of host genes involved in viral infection. We succeeded in establishing a cDNA-AFLP system to help track changes in gene expression patterns in N. benthamiana plants when infected with BaMV. The combination of both DNA-AFLP and VIGS methodologies made it possible to screen a large number of genes and identify those associated with infections of plant viruses. In this report, 9 of the 15 analyzed genes exhibited either a positive or a negative influence on the accumulation of BaMV in $\mathrm{N}$. benthamiana plants.
\end{abstract}

\section{Background}

Most steps involved in plant virus infection, such as the translation of viral genes, the replication of the viral genome and the movement of the viral genome/virion, involve interactions between relatively few viral components and a much more complex pool of host factors [1].

\footnotetext{
* Correspondence: chtsai1@dragon.nchu.edu.tw

'Graduate Institute of Biotechnology, National Chung Hsing University,

Taichung, 40227, Taiwan

Full list of author information is available at the end of the article
}

Studies of viral-host interactions provide insight into the life cycle of viruses and could help to devise strategies to tackle viral epidemics among plants. Identification of differentially expressed genes in plants during viral infection can help us to understand the defense systems employed by plants as well as the mechanisms behind the adaption of viruses to plant cells.

Plants are known to defend themselves against attacks from pathogens, such as viruses, bacteria, fungi, invertebrates, and sometimes other plants, by altering the host

\section{C) Biomed Central}


gene expression [2,3]. Compared to other pathogens, viruses are a particularly serious threat, due to their high mutation rate, which makes them better able to evade host defense systems. Plant viruses use a variety of strategies to promote infection in susceptible hosts. These strategies involve well-documented modifications to host cells such as the formation of replication complexes [4], the suppression of post-transcriptional gene silencing [5], alteration of cell-to-cell trafficking [6-9], and interference with the regulation of host cell cycle [10].

Plant viruses have three prerequisites to survive. First, they must replicate in the initially infected cell. Second, they must move into adjacent cells and the vascular system. Third, they must escape from or suppress the host defense system, by means such as post transcriptional gene silencing [11]. In turn, plants express resistance genes and/or activate systemic acquired resistance to fight the invading viruses [12]. These resistance responses typically involve dramatic changes in the expression of host proteins, such as pathogenesis related (PR) or hypersensitive response (HR) related genes, receptor-like kinases, and serine/threonine kinases [13].

Bamboo mosaic virus (BaMV), a single-stranded positive sense RNA virus, is a member of the potexvirus genus in the Flexsiviridae family. The 6366-nt genome of BaMV comprises a 5'-end $\mathrm{m}^{7} \mathrm{GpppG}$ structure, a 3'end poly (A) tail, 5'- and 3'-untranslated regions (UTR), and five open reading frames (ORF) [14]. ORF1 encodes a $155-\mathrm{kDa}$ polypeptide with three functional domains, i.e. the capping enzyme domain [15-17], an RNA helicase-like domain with RNA 5' triphosphotase and NTPase activities $[15,18,19]$, and an RNA-dependent RNA polymerase domain [20]. ORFs 2, 3 and 4, encoding proteins of 28,13 , and $6 \mathrm{kDa}$, respectively [14] are required for viral cell-to-cell movement $[21,22]$. The product of ORF5 is the $25-\mathrm{kDa}$ coat protein. Host factors, such as chloroplast phosphoglycerate kinase, which interacts with the BaMV 3' UTR (identified by UVcrosslinking), may play a positive role in the accumulation of BaMV accumulation in N. benthamiana [23]. A putative methyltransferase interacting with RdRp, identified by the yeast two-hybrid system plays a negative role in the accumulation of BaMV [23,24].

This study used cDNA-amplified fragment length polymorphism (AFLP) to identify differentially expressed genes during BaMV infection in $N$. benthamiana. The cDNA-AFLP technique is an efficient, sensitive, and reproducible technology offering several advantages over other PCR methodologies, such as a high degree of selectivity against rare mRNA species $[25,26]$. The Tobacco rattle virus (TRV)-based silencing system was used to knock down the expression of differentially expressed genes obtained by cDNA-AFLP. This study examines and discusses the effects of gene-specific knockdowns on BaMV infection.

\section{Results}

Screening of BaMV infection-induced genes in $\mathbf{N}$. benthamiana by cDNA-AFLP

Total RNA was extracted from the mock- and BaMVinoculated leaves $1,3,5$, and 7 days post inoculation, to identify differentially expressed genes in $N$. benthamiana plants following infection with BaMV. To avoid genomic contamination of the DNA and to enhance the efficiency of reverse transcription, we generated the cDNA from oligo (dT)-purified mRNAs and confirmed the efficiency of synthesizing cDNA on a $5 \%$ polyacrylamide gel before proceeding with the production of a standard cDNA-AFLP template [27].

To rule out false-positive signals in cDNA-AFLP, we compared the products from two different batches of mRNA, derived from two independent inoculation experiments together on the same gel. In this study, we used eight different primer pairs, T-AC/M-AC, T-AC/ M-AG, T-AC/M-CA, T-AC/M-CT, T-AC/M-GA, T-AC/M-GT, T-AC/M-TC, and T-AC/M-TG, to generate the cDNA expression profiles through selective amplification of PCR (Figure 1). Identifying the cDNA fragments of differential levels was simple when lined up together as shown in Figure 1, from which we analyzed the amplified products derived from the T-CA/MGA primer pair. We assigned positive bands only when the same banding profiles occurred in both batches. The eight primer pairs allowed detection of approximately 90 differentially expressed cDNA bands. Separation of these fluorescently labeled cDNA-AFLP fragments using $6.5 \%$ polyacrylamide sequencing gel, imaged with a fluorescent scanner, and eluted from the gel, identified 49 fragments for up-regulation and 41 for down-regulation, following inoculation with BaMV (Table 1).

\section{Identification of major cDNA species from bands containing multiple genes}

We next amplified and cloned the cDNA bands eluted from the cDNA-AFLP gels; DNA sequencing of 6 to 18 clones from each cloning revealed the identity of the cDNA inserts. Sequencing results from approximately 944 clones, indicated that two-thirds (62/90) of the cropped gel fragments contained cDNAs of multiple genes (Additional file 1). These results had been expected, because the gel fragments included any cDNAs in the region. Therefore, further analysis was required to confirm the identity of the genes differentially expressed between mock- and BaMV-inoculated samples.

Logically, the clone identified at the highest frequency using DNA sequencing would correspond to the 


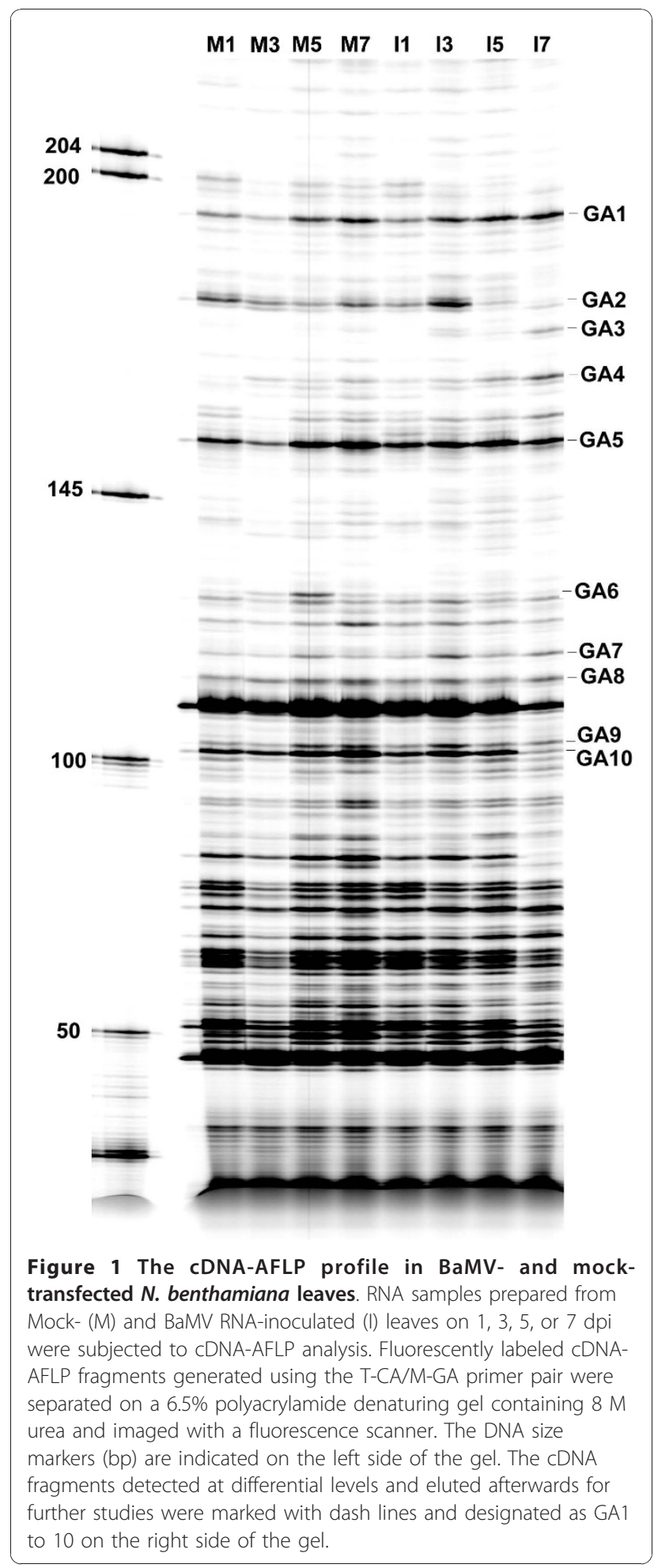

differentially expressed cDNA detected in each gel fragment (Additional file 1). However, there was the possibility of skewed efficiency in the process of cloning the cDNA fragments. Target-specific semi-quantitative RTPCR was performed to examine whether the expression
Table 1 A summary of the differentially expressed CDNA fragments isolated with each selective primer pair

\begin{tabular}{ccc}
\hline Selective primer & Up regulated & Down regulated \\
\hline T-AC/M-AC & 3 & 8 \\
T-AC/M-AG & 5 & 7 \\
T-AC/M-CA & 11 & 1 \\
T-AC/M-CT & 9 & 6 \\
T-AC/M-GA & 7 & 3 \\
T-AC/M-GT & 8 & 4 \\
T-AC/M-TC & 2 & 7 \\
T-AC/M-TG & 4 & 5 \\
\hline total & 49 & 41
\end{tabular}

pattern of the major cDNA species identified in each band, was correlated with the signals in the cDNA-AFLP profile (Figure 2). A third batch of independently inoculated plants provided the mRNA templates used for this experiment. We designed gene-specific primers according to the DNA sequences of the major CDNA clones for more than 10 bands (Additional file 1). Figure 2 shows representative results of RT-PCR analysis including those of ACAG2-1, ACCT8-1, ACCT2-1, and ACCT13. Overall, the expression patterns for all examined targets were consistent with those in the cDNA-AFLP profile. Therefore, we tentatively assigned the major cDNA species identified from each band as representative of cDNA in all 90 bands (Table 2).

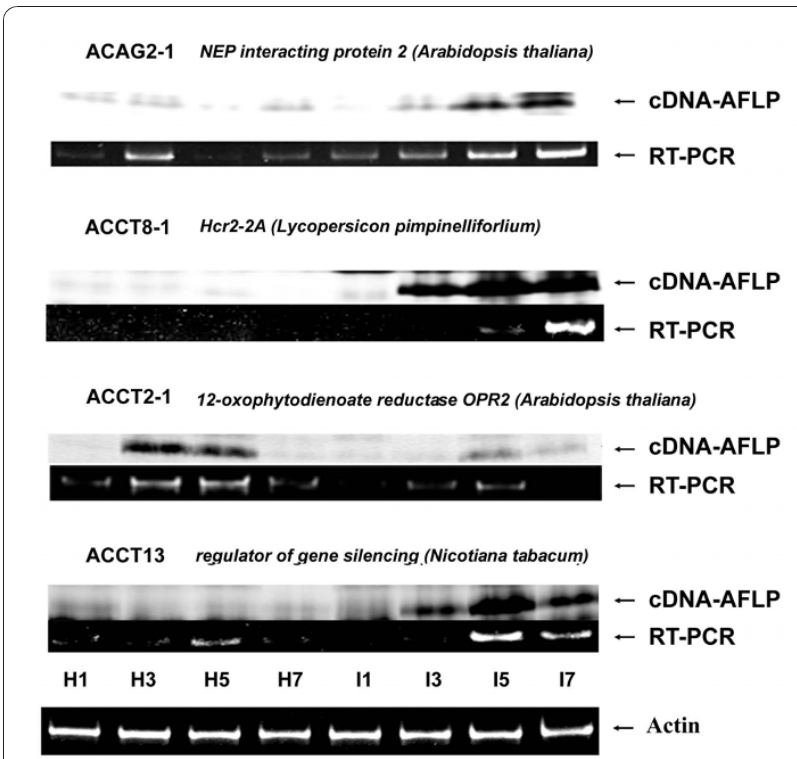

Figure 2 RT-PCR analysis of the expression profile of the cDNA-AFLP-derived CDNA fragments. ACAG2-1-, ACCT8-1-, ACCT2-1-, ACCT13-, and actin-specific RT-PCR analysis was carried out using RNA samples prepared from Mock- (M) and BaMV RNAinoculated (I) leaves on $1,3,5$, or $7 \mathrm{dpi}$. The corresponding signal in a cDNA-AFLP analysis is included for each target. 
Table 2 Transcript-derived fragments identified by cDNA-AFLP analysis and differentially expressed between Mockand Bamboo mosaic virus-inoculated Nicotiana benthamiana plants

\begin{tabular}{|c|c|c|c|c|c|c|}
\hline $\mathrm{TDF}^{\mathrm{a}}$ & ID & $\begin{array}{l}\text { Length } \\
\text { (bp) }\end{array}$ & Expression $^{c}$ & Protein candidate $^{d}$ & Ratio $^{\mathrm{e}}$ & $\begin{array}{c}E \\
\text { value }^{f}\end{array}$ \\
\hline \multicolumn{7}{|c|}{ Function: cell rescue, defense, death, and ageing: } \\
\hline ACTC1-1 & AAM08661.1 & 207 & - & putative disease resistance protein [Oryza sativa Japonica] & $9 / 15$ & \\
\hline ACTC3-1 & AAP03879.1 & 174 & - & Avr9/Cf-9 rapidly elicited protein 216 [Nicotiana tabacum] & $13 / 17$ & $1 e-05$ \\
\hline ACTG3-1 & AAB36652.1 & 213 & + & immediate-early salicylate-induced [Nicotiana tabacum] & $4 / 7$ & $5 e-19$ \\
\hline ACCT8-1 & AAC78594.1 & 129 & + & Hcr2-2A [Solanum pimpinellifolium] & 10/12 & $5 e-04$ \\
\hline ACCT10 & AAA74119.1 & 121 & + & SR1 Nt-rab7b [Nicotiana tabacum] & $12 / 12$ & $5 e-04$ \\
\hline ACAC6 & CAA72515.1 & 205 & + & heat shock protein [Arabidopsis thaliana] & $7 / 7$ & $1 e-21$ \\
\hline ACAC8-1 & ACG31454.1 & 144 & - & mpv17/PMP22 family protein [Zea mays] & $5 / 10$ & \\
\hline ACTC8-1 & ACG42715.1 & 120 & - & mpv17/PMP22 family protein [Zea mays] & $12 / 13$ & \\
\hline ACCT13 & AAK11255.1 & 114 & + & regulator of gene silencing [Nicotiana tabacum] & 10/10 & $5 e-04$ \\
\hline ACGT10 & CAD30209.1 & 140 & + & putative auxin-induced protein 29 [Arabidopsis thaliana] & $10 / 10$ & \\
\hline ACGT4 & AAN63619.1 & 188 & + & thioredoxin h-like protein [Nicotiana tabacum] & $6 / 6$ & 4e-09 \\
\hline ACCT14-1 & AAC06242.1 & 102 & - & late embryogenis abundant protein 5 [Nicotiana tabacum] & $5 / 12$ & 4e-03 \\
\hline ACCT12-1 & ABH09088.1 & 116 & - & putative membrane protein [Artemisia annua] & $6 / 8$ & $9 e-14$ \\
\hline ACGT11-1 & CAA69901.1 & 118 & + & plasma membrane polypeptide [Nicotiana tabacum] & $8 / 10$ & 1e-05 \\
\hline ACGA8-1 & AAF24496.1 & 93 & + & FH protein NFH1 [Nicotiana tabacum] & $6 / 8$ & \\
\hline ACAG2-1 & CAC81898.1 & 218 & + & NEP1-interacting protein 2 [Arabidopsis thaliana] & $9 / 10$ & $5 e-07$ \\
\hline ACCA5-1 & AAK40224.1 & 190 & + & putative syntaxin of plants 52 [Oryza sativa Japonica] & $8 / 10$ & 1e-08 \\
\hline ACCA7-1 & ABG73415.1 & 185 & + & chloroplast pigment-binding protein CP29 [Nicotiana tabacum] & $5 / 10$ & $4 \mathrm{e}-05$ \\
\hline ACCA8 & ABD28323.2 & 183 & + & excinuclease $A B C, C$ subunit[Medicago truncatula] & $8 / 8$ & $4 e-08$ \\
\hline ACCA1-1 & AAX95717.1 & 253 & + & protease inhibitor/seed storage/LTP family [Oryza sativa Japonica] & $5 / 10$ & \\
\hline ACCA10 & AAM73656.1 & 168 & + & AER [Nicotiana tabacum] & $6 / 6$ & $2 e-22$ \\
\hline ACAG4-1 & AAD32145.1 & 176 & - & Nt-iaa4.5 deduced protein [Nicotiana tabacum] & $9 / 10$ & 3e-05 \\
\hline \multicolumn{7}{|c|}{ Function: signal transduction: } \\
\hline ACCT1-1 & CAX43672.1 & 322 & - & CDK-activating kinase[Candida dubliniensis CD36] & $6 / 9$ & \\
\hline ACCT7-1 & BAF62637.1 & 135 & + & DELLA protein [Phaseolus vulgaris] & $10 / 12$ & $4 e-15$ \\
\hline ACTG7-1 & ABD34616.1 & 127 & - & green ripe-like 1 [Solanum lycopersicum] & $5 / 10$ & $5 e-04$ \\
\hline ACCA2-1 & AAS20952.1 & 204 & + & calmodulin binding protein 25 [Arabidopsis thaliana] & $6 / 10$ & $5 e-06$ \\
\hline \multicolumn{7}{|c|}{ Function: transcription: } \\
\hline ACAC2 & ABO42262.1 & 249 & - & AT-hook DNA-binding protein [Gossypium hirsutum] & $8 / 8$ & $3 e-04$ \\
\hline ACGA4-1 & AAL66977.1 & 141 & + & $\begin{array}{l}\text { putative cleavage and polyadenylation specificity factor [Arabidopsis } \\
\text { thaliana] }\end{array}$ & $8 / 10$ & \\
\hline ACCA6 & AAM65499.1 & 186 & + & AP2 domain transcription factor [Arabidopsis thaliana] & $8 / 8$ & $2 e-05$ \\
\hline ACAG11-1 & BAC79914.1 & 57 & - & homeobox transcription factor Hox7-like protein [Oryza sativa Japonica] & $5 / 10$ & \\
\hline ACGA5 & AAM14969.1 & 135 & - & putative small nuclear ribonucleoprotein Prp4p [Arabidopsis thaliana] & $7 / 7$ & \\
\hline ACCT4-1 & AAB62807.1 & 220 & + & S-adenosyl-methionine-sterol-C-methyltransferase [Nicotiana tabacum] & $6 / 12$ & $2 e-34$ \\
\hline ACGT1 & AAK13103.1 & 285 & - & helicase-like protein [Oryza sativa Japonica] & $6 / 6$ & $2 e-03$ \\
\hline ACGT5-1 & AAA35148.1 & 183 & + & transcription factor IIIB [Saccharomyces cerevisiae] & $6 / 15$ & 3e-05 \\
\hline \multicolumn{7}{|c|}{ Function: metabolism } \\
\hline ACCT5-1 & ACG37370.1 & 193 & - & lysine ketoglutarate reductaselysine trans-splicing [Zea mays] & $7 / 12$ & $2 e-29$ \\
\hline ACTG1-1 & ACD13145.1 & 277 & - & TOK1 potassium channel [Aspergillus fumigatus] & $7 / 10$ & \\
\hline ACAC7-1 & AAS46243.1 & 149 & - & xyloglucan endotransglucosylase-hydrolase XTH7 [Solanum lycopersicum] & $5 / 9$ & $1 e-13$ \\
\hline ACCA11-1 & ABN09771.1 & 139 & - & glycosyl transferase, family 48 [Medicago truncatula] & $10 / 16$ & $1 e-13$ \\
\hline ACTC4-1 & AAA34065.1 & 169 & - & chloroplast carbonic anhydrase [Nicotiana tabacum] & 10/18 & $6 e-15$ \\
\hline ACAG10 & AAA34065.1 & 79 & - & chloroplast carbonic anhydrase [Nicotiana tabacum] & 10/10 & $1 e-07$ \\
\hline ACAG8 & AAY17071.1 & 108 & - & chloroplast carbonic anhydrase [Nicotiana benthamiana] & $6 / 6$ & $5 e-21$ \\
\hline ACGA10-1 & BAA25639.1 & 76 & - & NPCA1 [Nicotiana paniculata] & $8 / 10$ & $8 e-04$ \\
\hline \multicolumn{7}{|c|}{ Function: energy } \\
\hline ACGA9 & AAD25541. & 84 & + & fructose-1,6-bisphosphatase precursor [Solanum tuberosum] & $8 / 8$ & $9 \mathrm{e}-08$ \\
\hline ACGT2-1 & CAA41713.1 & 193 & - & photosystem II 23 kDa polypeptide [Nicotiana tabacum] & $5 / 6$ & $3 e-20$ \\
\hline ACGT3-1 & AAA34053.1 & 190 & + & beta-1,3-glucanase [Nicotiana tabacum] & $5 / 6$ & $2 e-15$ \\
\hline ACGT8-1 & CAJ32461.1 & 160 & + & putative chloroplast cysteine synthase 1 [Nicotiana tabacum] & $10 / 15$ & $1 e-08$ \\
\hline
\end{tabular}


Table 2 Transcript-derived fragments identified by CDNA-AFLP analysis and differentially expressed between Mockand Bamboo mosaic virus-inoculated Nicotiana benthamiana plants (Continued)

\begin{tabular}{|c|c|c|c|c|c|c|}
\hline ACGT9-1 & CAX42612.1 & 143 & + & NADPH-dependent 1-acyl dihydroxyacetone [Candida dubliniensis CD36] & $7 / 10$ & $3 e-23$ \\
\hline ACAG5-1 & AAM28014.1 & 158 & + & granule-bound starch synthase [Peraphyllum ramosissimum] & $7 / 16$ & $1 e-07$ \\
\hline ACCA4 & BAA28625.1 & 194 & + & aldehyde oxidase [Arabidopsis thaliana] & 10/10 & 2e-07 \\
\hline ACAG1 & CAA74359.1 & 269 & - & ferredoxin-NADP(+) reductase [Nicotiana tabacum] & $10 / 10$ & $7 e-38$ \\
\hline ACTC2 & AAB39547.1 & 199 & - & polygalacturonase isoenzyme 1 beta subunit [Solanum lycopersicum] & $14 / 14$ & $1 e-28$ \\
\hline ACCT2-1 & AAC78441.1 & 295 & - & 12-oxophytodienoate reductase OPR2 [Arabidopsis thaliana] & $7 / 8$ & $2 e-32$ \\
\hline ACGT12 & CAA44267.1 & 115 & - & lipid transferase [Nicotiana tabacum] & $8 / 8$ & $6 e-10$ \\
\hline ACAG9 & CAA44267.1 & 97 & - & lipid transferase [Nicotiana tabacum] & 10/10 & $7 e-08$ \\
\hline \multicolumn{7}{|c|}{ Function: translation } \\
\hline ACTC5-1 & CAA77372.1 & 149 & - & ribosomal protein L20 [Nicotiana tabacum] & $6 / 17$ & $2 e-11$ \\
\hline ACTG5-1 & ABN08437.1 & 135 & + & ribosomal protein L10 [Medicago truncatula] & $7 / 10$ & $9 e-16$ \\
\hline ACGA2-1 & CAA77381.1 & 154 & + & ribosomal protein S3 [Nicotiana tabacum] & 10/17 & $1 e-03$ \\
\hline ACGT7-1 & CAA77408.1 & 165 & + & ribosomal protein L23 [Nicotiana tabacum] & $6 / 10$ & 2e- -25 \\
\hline \multicolumn{7}{|c|}{ Function: unclassified } \\
\hline ACTC9-1 & BAC98856.1 & 117 & - & hypothetical protein [Brassica napus] & $5 / 12$ & $5 e-06$ \\
\hline ACTG9 & AAW82556. & 109 & - & hypothetical protein [Phalaenopsis aphrodite subsp. formosana] & $14 / 14$ & \\
\hline ACAC1-1 & CAN77388.1 & 299 & - & hypothetical protein [Vitis vinifera] & $14 / 15$ & $4 e-41$ \\
\hline ACAC5-1 & CAN79807.1 & 240 & - & unknown protein [Vitis vinifera] & $8 / 10$ & $8 e-04$ \\
\hline ACCT3-1 & CAJ32479.1 & 270 & - & hypothetical protein [Nicotiana tabacum] & $5 / 10$ & $1 e-06$ \\
\hline АCСТ9-1 & AAK20059.1 & 126 & + & hypothetical protein [Oryza sativa Japonica] & $6 / 10$ & \\
\hline ACGA1-1 & ABW98323.1 & 174 & + & hypothetical protein [Hemiselmis andersenii] & $10 / 15$ & \\
\hline ACCA3 & CAA45741.1 & 200 & + & mRNA C-7 [Nicotiana tabacum] & $8 / 8$ & $6 e-11$ \\
\hline ACAG6 & BAD46202.1 & 131 & + & hypothetical protein [Oryza sativa Japonica] & $8 / 8$ & \\
\hline ACCA9-1 & AAM91702.1 & 174 & + & unknown protein [Arabidopsis thaliana] & $4 / 12$ & $5 e-14$ \\
\hline \multicolumn{7}{|c|}{ No significant match } \\
\hline ACTG4 & & 148 & + & No significant match & $8 / 8$ & \\
\hline ACTG6 & & 134 & - & No significant match & $8 / 8$ & \\
\hline ACTG2-1 & & 271 & - & No significant match & $5 / 12$ & \\
\hline ACAC3 & & 246 & - & No significant match & $7 / 7$ & \\
\hline ACAC4-1 & & 245 & + & No significant match & $4 / 7$ & \\
\hline ACTG8-1 & & 117 & + & No significant match & $4 / 12$ & \\
\hline ACAC9-1 & & 138 & + & No significant match & $5 / 8$ & \\
\hline ACAC11 & & 118 & - & No significant match & $8 / 8$ & \\
\hline ACAC10-1 & & 123 & - & No significant match & $7 / 12$ & \\
\hline ACCT6-1 & & 151 & + & No significant match & $10 / 12$ & \\
\hline ACCT11-1 & & 119 & + & No significant match & $10 / 12$ & \\
\hline ACGA3-1 & & 151 & + & No significant match & $6 / 10$ & \\
\hline ACCT15-1 & & 96 & + & No significant match & $6 / 12$ & \\
\hline ACTC6-1 & & 135 & + & No significant match & $9 / 18$ & \\
\hline ACTC7-1 & & 130 & + & No significant match & $6 / 12$ & \\
\hline ACGA6-1 & & 107 & - & No significant match & $7 / 14$ & \\
\hline ACGA7 & & 97 & + & No significant match & $8 / 8$ & \\
\hline ACGT6 & & 181 & - & No significant match & $8 / 8$ & \\
\hline ACAG7-1 & & 115 & - & No significant match & $5 / 8$ & \\
\hline ACAG3-1 & & 186 & + & No significant match & $7 / 12$ & \\
\hline ACCA12-1 & & 126 & + & No significant match & $10 / 14$ & \\
\hline ACAG12-1 & & 47 & + & No significant match & $6 / 10$ & \\
\hline
\end{tabular}

${ }^{\mathrm{a}} \mathrm{TDF}$ : transcript-derived fragment.

bID: accession number of analogues identified by Tblastx.

'Expression: up-regulated (+) or down-regulated (-) CDNA-AFLP signals detected in virus-infected leaves, compared to mock-infected leaves ${ }^{\mathrm{d} P r o t e i n}$ candidate: Tblastx hit with the best $\mathrm{E}$ value.

'Ratio: the number of the clone over the number of total clones sequenced.

${ }^{\mathrm{f} E}$ value: only the value lower than 0.001 (1e-03) were shown according to statistic analysis with extremely significant hit. 


\section{Sequence analysis of differentially expressed cDNA fragments}

Sequence analysis of the major cDNA species listed in Table 2 revealed that twenty-two of the 90-cDNA fragments shared no significant homology with any known sequences found in the databases. On the other hand, we found analogs for 68 cDNA fragments of which more than two-thirds were sequences derived from $N$. tabacum, Arabidopsis, and rice (Table 2). Among these, 53 led to blast matches of biological significance as suggested by the E-values (Table 2). Table 2 lists the genes categorized according to function: twenty-two genes were involved in cell rescue, defense, death, and aging; 12 in energy; 8 in transcription; 8 in metabolism; 4 in translation; 4 in signal transduction, and 10 could not be classified. Interestingly, three of the genes, namely the mpv17/PMP22 family protein (ACAC8-1 and ACTC8-1), chloroplast carbonic anhydrase (ACAG8, ACAG10, and ACTC4-1), and lipid transferase (ACGT12 and ACAG9) were isolated from different selective primer sets, which remarkably led to identical cDNA-AFLP expression patterns for each target (Table 2). These results implied that the cDNA-AFLP technique is a reliable and reproducible means to identify differentially expressed genes.

\section{Effect of gene-specific knockdown on the accumulation of BaMV}

To investigate the roles of the differentially expressed genes identified by cDNA-AFLP analysis in BaMV infection cycle, the TRV VIGS system [28], which has been used widely to knock down homologous genes in
$N$. benthamiana [29], was adopted to generate genespecific knockdown plants. We evaluated the effects of lowered expression levels of individual host genes on the replication of BaMV, i.e. viral RNA and the accumulation of protein.

To assess the effect of the TRV vector in N. benthamiana, GFP or Luciferase ORF (non plant-derived DNA) were introduced to the PTRV2 vector to serve as a control. Fifteen genes, picked randomly from each assigned functional category (Table 2) for knockdown experiments showed no significant effect on plant growth or development. Most of these knockdown plants (Table 3) exhibited no difference in morphology to that of the control plants (Figures 3 and Additional file 2). However, yellowing mosaics occurred on leaves of the ACAG1 (a putative ferredoxin-NADP ${ }^{+}$reductase; FNR) of the knockdown plants (Figure 3). The results of the studies of BaMV regarding ACAG1 and ACAG8 (a putative chloroplast carbonic anhydrase, $c C A$ ) in the knockdown plants are described here to represent our observations of these 15 knockdown plants (Figures 3 and 4). We used semi-quantitative RT-PCR to assess the knockdown efficiency of the VIGS system (Figures 5 and Additional file 2) and Western blot analysis to determine the accumulation of BaMV coat protein in the inoculated leaves. Results indicate that mRNA levels of the FNR gene were reduced to $47 \%$ that of the control plants (Figure 4A). Western blot analysis of BaMV coat protein detected a nearly two-fold accumulation in 5 dpi samples in these plants (Figure 4B). The mRNA levels of the $c C A$ gene were reduced to $76 \%$ (significance in $t$-test) in the knockdown plants (Figure 4C) leading to

Table 3 BaMV coat protein accumulation in TRV-driven gene-silenced Nicotiana benthamiana plants

\begin{tabular}{|c|c|c|c|c|}
\hline $\mathrm{TDF}^{\mathrm{a}}$ & Expression $^{\mathbf{b}}$ & Protein candidate & $\mathrm{CP}^{\mathrm{c}}$ & Significance $^{d}$ \\
\hline ACCT13 & + & regulator of gene silencing $[N$. tabacum] & $72 \pm 3$ & \\
\hline ACGT4 & + & thioredoxin h-like protein [N. tabacum] & $181 \pm 43$ & ** \\
\hline ACGT11-1 & + & plasma membrane polypeptide [N. tabacum] & $172 \pm 49$ & ** \\
\hline ACAG2-1 & + & NEP1-interacting protein 2 [Arabidopsis thaliana] & $191 \pm 14$ & *** \\
\hline ACCA10 & + & AER [N. tabacum] & $77 \pm 32$ & \\
\hline ACCT1-1 & - & CDK-activating kinase[Candida dubliniensis CD36] & $197 \pm 25$ & ** \\
\hline ACCT5-1 & - & lysine ketoglutarate reductaselysine trans-splicing [Zea mays] & $74 \pm 24$ & \\
\hline ACAG8 & - & chloroplast carbonic anhydrase $[N$. benthamiana] & $68 \pm 14$ & * \\
\hline ACGT2-1 & - & photosystem II 23 kDa polypeptide [N. tabacum] & $149 \pm 40$ & ** \\
\hline ACAG1 & - & ferredoxin-NADP $(+)$ reductase $[N$. tabacum $]$ & $190 \pm 24$ & $* *$ \\
\hline ACGT12 & - & lipid transferase [N. tabacum] & $42 \pm 18$ & $* * *$ \\
\hline ACTC5-1 & - & ribosomal protein L20 [N. tabacum] & $73 \pm 17$ & \\
\hline ACCT3-1 & - & hypothetical protein [N. tabacum] & $70 \pm 30$ & \\
\hline ACCA3 & + & mRNA C-7 [N. tabacum] & $56 \pm 26$ & ** \\
\hline ACGA3-1 & + & No significant match & $107 \pm 16$ & \\
\hline
\end{tabular}

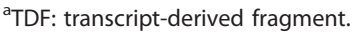

${ }^{b}$ Expression: up-regulated (+) or down-regulated (-) cDNA-AFLP signals detected in virus-infected leaves, compared to mock-infected leaves.

${ }^{\mathrm{c}} \mathrm{CP}$ : the coat protein accumulation levels of BaMV in knockdown plants.

${ }^{\mathrm{d}}$ Significance: Asterisks indicate statistically significant differences compared with the control plants $\left({ }^{*} \mathrm{p}<0.05,{ }^{* *} \mathrm{p}<0.01,{ }^{* * *} \mathrm{p}<0.001\right)$. 


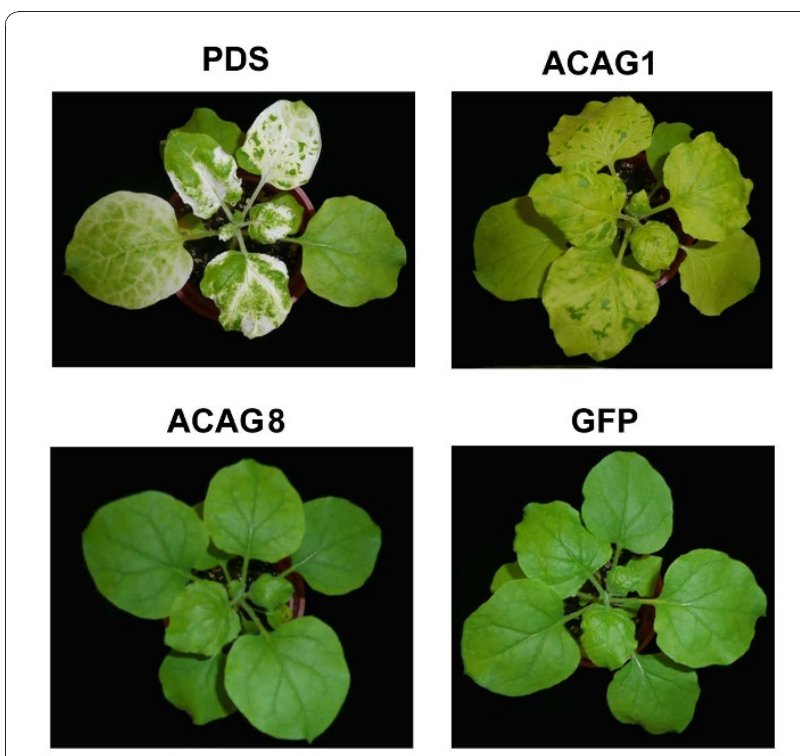

Figure 3 Phenotypes of gene-specific knockdown plants generated by the TRV VIGS system. Transcription of ACAG1 and ACAG8 in N. benthamiana plant was introduced by the TRV vector to knock down expression of the corresponding host genes. The PDS plant in which phytoene desaturase was knocked down served as a positive control. The GFP plant in which the green fluorescent protein gene was introduced was included as a negative control.

a reduction in the accumulation of coat protein to $63 \%$ that of the control plants (Figure 4D). These results suggest that FNR might play a role preventing the accumulation of BaMV, whereas $c C A$ could facilitate the accumulation of BaMV.

Among the 15 genes analyzed (by VIGS knockdown experiments), we found that the levels of accumulated coat protein significantly increased in six knockdown plants suggesting that these six genes play a role in counteracting BaMV infection (Figures 5A and Table 3). Three knockdown plants showed a significant reduction in the level of coat protein, implying that these three genes play a positive role in the accumulation of BaMV in plants. No statistically significant difference was shown between the six remaining knockdown plants and the control plants when inoculated with BaMV. Interestingly, all of the genes playing a potentially negative role in the accumulation of BaMV within the categories related to cell rescue, defense, death, ageing, signal transduction, and energy. These results suggest that the proteins involved in signal transduction pathways related to pathogen defense might be involved in resistance to BaMV in $N$. benthamiana plants. Finally, approximately three-fifths of the 15 randomly picked, differentially expressed genes showed either a positive or a negative influence on the accumulation of BaMV in plants.

\section{Discussion}

The Arabidopsis genetic system is a common choice for the identification of plant genes involved in the interactions with plant-pathogens. Lately, other genomic-scale methods, such as cDNA-AFLP, serial analysis of gene expression, cDNA microarray, and proteomics have been developed to study the interactions associated with plant-pathogens [30]. Among these, cDNA-AFLP is useful in detecting differentially expressed genes when genome sequence or microarray data is unavailable [25]. This method employs two restriction enzymes to generate short fragments in the analysis of AFLP. The choice of restriction enzyme depends on the complexity of the target templates [25]. Commonly, cleavage in cDNA templates involves the use of four-base cutter enzymes to generate fragments of ideal sizes (0.1-1.0 kb). Because of the relatively low complexity of the cDNA, two selective bases for each primer enabled 256 possible primer combinations [25]. With commercially available resources and a few modifications, a high-throughput gene expression detection system can be easily established [13].

In this study, we used eight pairs of primers in the cDNA-AFLP analysis, to isolate 90 differentially expressed genes in BaMV-inoculated plants. However, one of the major drawbacks of this technique is that each banding from the AFLP reaction could comprise more than one cDNA fragment. Therefore, it is important to confirm differential expression of the targets identified by cDNA-AFLP, using techniques such as real time RT-PCR, semi-quantitative RT-PCR, or Northern blotting. Three different batches of mRNAs (two for cDNA-AFLP and the third for confirmation) were extracted from $N$. benthamiana plants prepared independently to reduce the risk of false positive results. Another drawback was that the sequencing of the genome of $N$. benthamiana, the experimental plant used in this study, is not yet complete. Many cDNA fragments of $N$. benthamiana identified by the cDNA-AFLP analysis had no significant match in the database. Although a work around approach is available, in which Arabidopsis or rice is used as the host plant, $N$. bentamiana is still a more suitable organism for the study of BaMV life cycle. Furthermore, host gene expressions in $N$. benthamiana can be knocked down by the VIGS systems $[28,29,31]$ to determine whether these differentially expressed genes have any influence on the accumulation of BaMV.

Knocking down the expression levels of these host genes using the VIGS system enables the identification of the novel functions of genes in pathogen-host interactions. FNR is down regulated upon infection with BaMV (Table 2). The leaves of FRN knockdown plants display discoloration similar to that induced by BaMV 
A

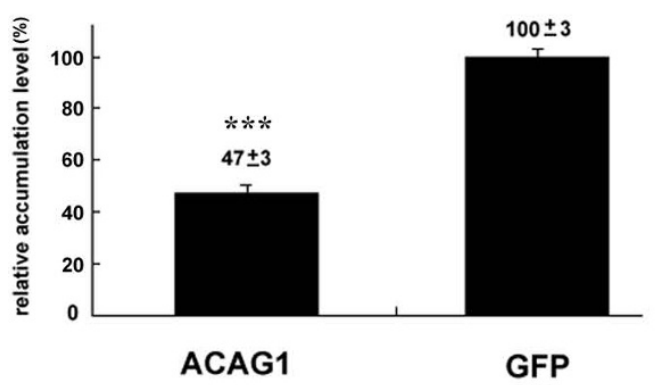

ACAG1

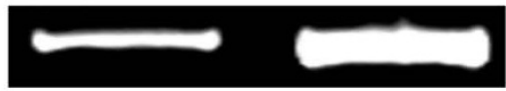

actin

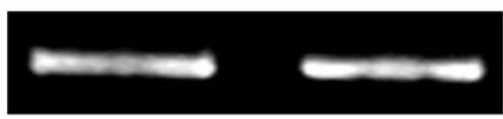

B

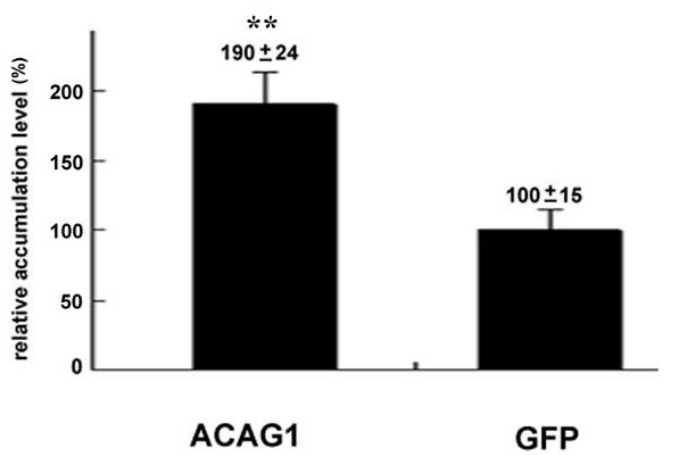

coat protein
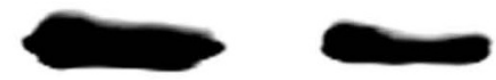

rbcL

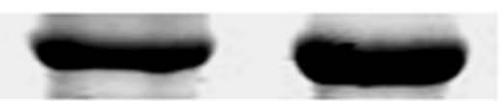

Figure 4 RT-PCR analysis of host gene expression and Western blotting analysis of BaMV coat protein accumulation in ACAG1- and ACAG8-knockdown plants. ACAG1- and ACAG8-knockdown plants were inoculated with viral RNA. The GFP plant was included as the negative control. RNA and protein extracts of leaves inoculated with viral RNA were harvested on $5 \mathrm{dpi}$. The RNA extracts were subjected to ACAG1- (A) or ACAG8-specific (C) semi-quantitative RT-PCR. RT-PCR data was normalized to the levels of actin. Protein extracts were analyzed for BaMV coat protein accumulation by Western blotting (B and D). The Rubisco large subunit (rbcL) was included as the loading control for normalization. For al experiments, the levels detected in the GFP control plants on 5 dpi were set as 100\%. Representative results are shown under the statistical results showing the average of the relative levels of AGAC1 mRNA (A), ACAG8 mRNA (C) and, BaMV coat protein (B and D) with standard deviations derived from at least three independent experiments. Asterisks indicate statistically significant differences compared with the control indicated as GFP $\left({ }^{* *} p<0.05,{ }^{* * *} p<0.001\right)$.
C

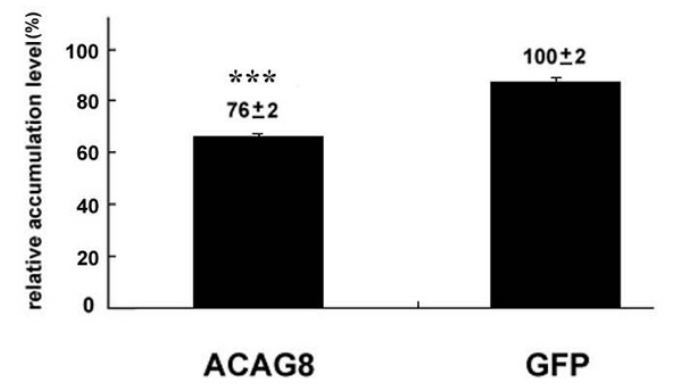

actin

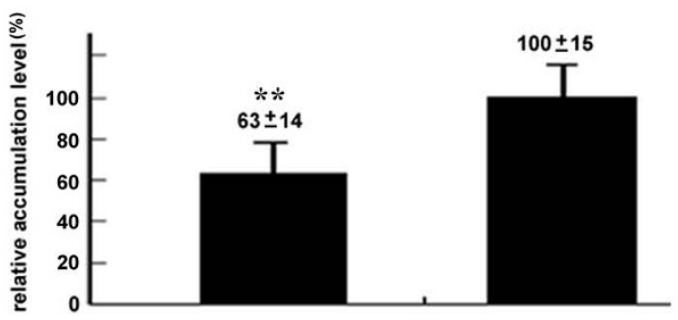

ACAG8

GFP

coat protein

rbcL

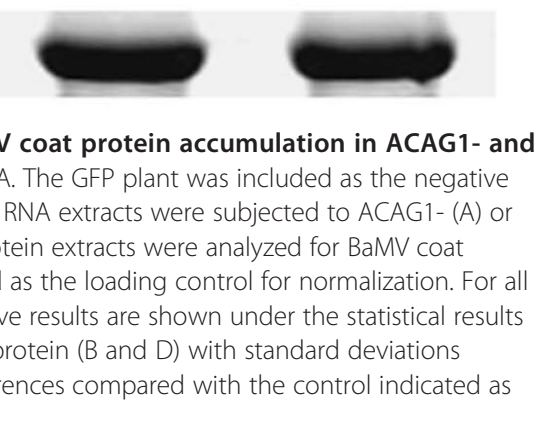

ACAG8 


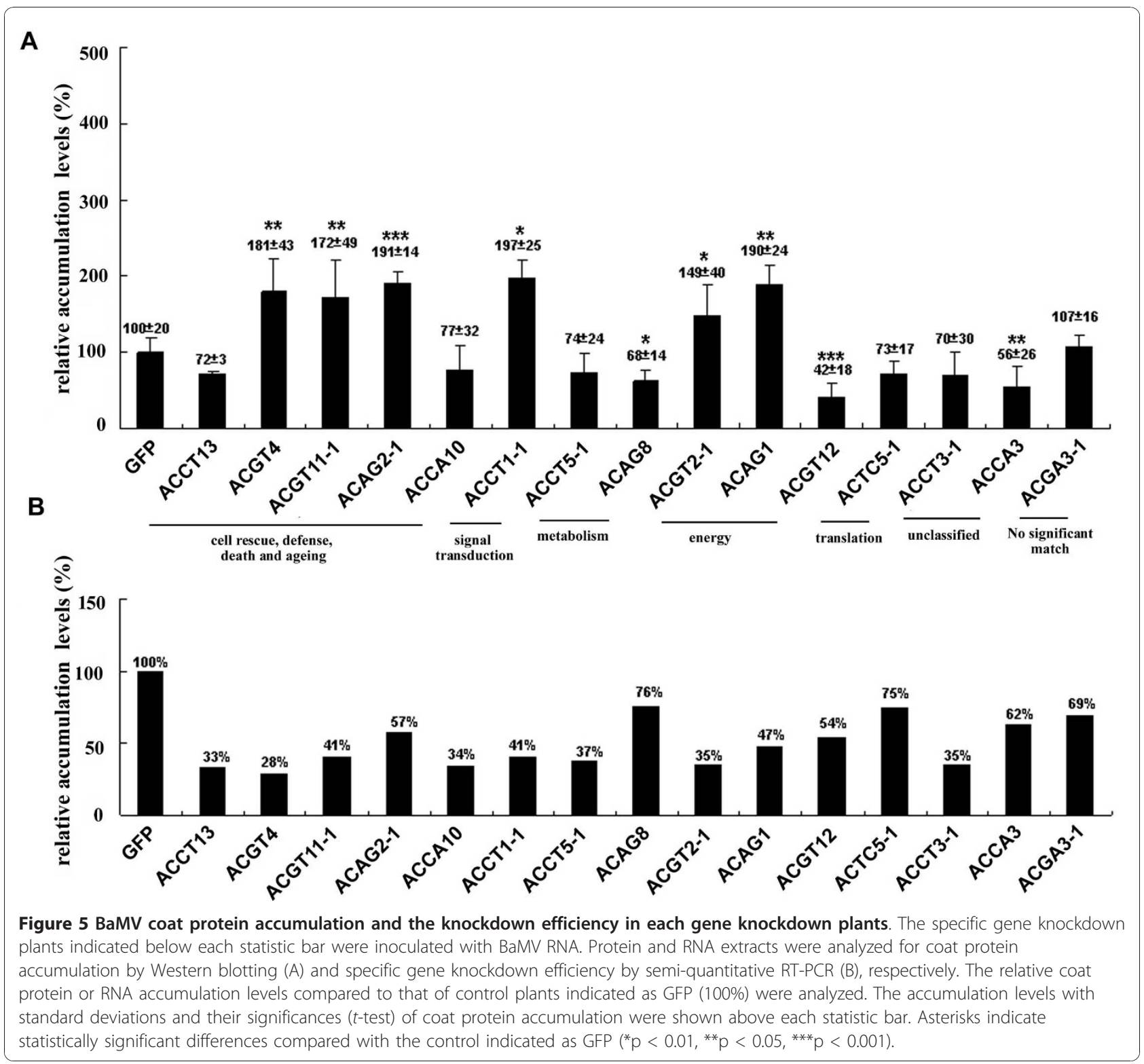

infection in control plants (Figure 3), suggesting that FNR may be involved in the development of viral symptoms. FNR may also be a gene associated with innate plant immunity capable of suppressing the accumulation of BaMV, as suggested by the observation that FNR knockdown plants shows elevated levels of viral products compared to infected control plants. On the other hand, the expression of the $\mathrm{cCA}$, which catalyzes reversible hydration of $\mathrm{CO}_{2}$ in plants, down regulates in response to infection with BaMV. Future investigations could test the hypothesis that FNR is a gene associated with innate immunity by studying plants that transiently or permanently over-express $F N R$, to evaluate the effects of higher levels of host FNR on the replication of BaMV. Lower levels of accumulated BaMV were detected in $c C A$ knockdown plants (Figure 4), suggesting that $\mathrm{cCA}$ could be recruited by BaMV to facilitate viral replication. Examination of the effects of $c C A$ overexpression on BaMV replication in plants would test this hypothesis.

ACAG2 is another potential pathogen defense gene enhancing the accumulation of BaMV coat protein approximately 2 folds, when knocked down in $N$. benthamiana plants. We have predicted that ACAG2 is a nuclear-encoded polymerase (NEP) interacting-protein (NIP) containing three transmembrane domains and one RING-H2 domain. The RING domain is reported to interact with E3-ubiquitin ligases mediating ubiquitination and degradation of the protein by the proteasome [32]. 


\section{Conclusions}

The VIGS system helps to identify the roles of differentially expressed genes associated with BaMV infection. We have succeeded in establishing a cDNA-AFLP system to help track the changes involved in gene expression patterns in $N$. benthamiana plants during viral infection. In total, 90 differentially expressed genes were uncovered using eight primer pairs in the analysis in BaMV-infected $N$. benthamiana. Combining both cDNA-AFLP and VIGS methodologies, makes the screening of large numbers of genes possible, to identify those playing a critical role in plant virus infection. In this report, 9 of the 15 genes analyzed exhibited either a positive or a negative influence on the accumulation of BaMV in N. benthamiana plants.

\section{Methods}

\section{Plant material and viral inoculation}

Plants (Nicotiana benthamiana) were grown in a growth chamber with a $16 \mathrm{~h}$ day length at $28^{\circ} \mathrm{C}$. Six-week-old plants were mechanically inoculated with $500 \mathrm{ng}$ of BaMV on each leaf. Virus- and mock-inoculated leaves were harvested on day 1, 3, 5 or 7 post-inoculation (dpi).

\section{Plant mRNAs isolation}

Total RNA was extracted from $3 \mathrm{~g}$ of leaves. The leaves were ground to powder with liquid nitrogen and mixed with $6 \mathrm{ml}$ of STE buffer (100 mM Tris-HCl, pH 8.0, 100 $\mathrm{mM} \mathrm{NaCl}$ and $10 \mathrm{mM}$ EDTA), $660 \mu \mathrm{l}$ of $10 \%$ SDS and $180 \mu \mathrm{l}$ of $100 \mathrm{mg} / \mathrm{ml}$ bentonite. The mixture was centrifuged at $12000 \mathrm{rpm}$ for $10 \mathrm{~min}$ at $4^{\circ} \mathrm{C}$ (Sigma model $3 \mathrm{MK}$ centrifuge) after three times of phenol/chloroform extraction. Total RNA in the supernatant was ethanol precipitated, stored at $-80^{\circ} \mathrm{C}$, and subjected to poly $(\mathrm{A})$ RNA isolation by using oligo(dT)-coupled paramagnetic beads. Briefly, $100 \mu \mathrm{l}$ of the total RNA $(75 \mu \mathrm{g})$ were heated at $65^{\circ} \mathrm{C}$ for $2 \mathrm{~min}$ to disrupt secondary structure and then placed on ice. About $200 \mu \mathrm{l}$ of Dynabeads Oligo (dT)25 (Dynal A.S., Oslo, Norway) were washed twice with $100 \mu \mathrm{l}$ of binding buffer $(20 \mathrm{mM}$ Tris- $\mathrm{HCl}$ $\mathrm{pH} 7.5,1.0 \mathrm{M} \mathrm{LiCl}, 2 \mathrm{mM}$ EDTA) and resuspended in $100 \mu \mathrm{l}$ of binding buffer. The beads were incubated with total RNA for 3-5 min at room temperature, washed twice with $200 \mu \mathrm{l}$ of washing buffer $(10 \mathrm{mM}$ Tris- $\mathrm{HCl}$ $\mathrm{pH} 7.5,0.15 \mathrm{M} \mathrm{LiCl}, 1 \mathrm{mM}$ EDTA) and resuspend in $10 \mu \mathrm{l}$ of deionized water to elute the mRNA.

\section{CDNA synthesis}

For the first-strand cDNA synthesis, the $20-\mu \mathrm{l}$ reaction containing $750 \mathrm{ng}$ of mRNA, 30 pmole of Oligo $(\mathrm{dT})_{40}$, $50 \mathrm{mM}$ Tris- $\mathrm{HCl} \mathrm{pH} 8.3,75 \mathrm{mM} \mathrm{KCl}, 3 \mathrm{mM} \mathrm{MgCl}{ }_{2}$, $1 \mathrm{mM}$ dNTP, $10 \mathrm{mM}$ DTT, and $1 \mu \mathrm{l}$ of $200 \mathrm{U} / \mu \mathrm{l}$ SuperScript ${ }^{\circledR}$ III Reverse Transcriptase (Invitrogen, Carlsbad,
CA, USA)was incubate at $42^{\circ} \mathrm{C}$ for $90 \mathrm{~min}$. Following removal of the mRNA by alkaline lysis, the cDNA was ethanol precipitated, washed, dried, and dissolved in $10 \mu \mathrm{l}$ of deionized water. The second-strand cDNA was synthesized in a $10-\mu \mathrm{l}$ reaction containing $4 \mu \mathrm{l}$ of firststrand cDNA, $10 \mathrm{mM}$ Tris- $\mathrm{HCl}$ (pH 7.5), $5 \mathrm{mM} \mathrm{MgCl}_{2}$, $7.5 \mathrm{mM}$ DTT, $10 \mathrm{mM}$ dNTP, and 2.5 units of Klenow polymerase (New England Biolabs, Beverly, MA, USA) at $25^{\circ} \mathrm{C}$ for $30 \mathrm{~min}$. The enzyme was inactivated with $100 \mathrm{mM}$ EDTA for $20 \mathrm{~min}$ at $75^{\circ} \mathrm{C}$.

\section{CDNA-AFLP}

cDNA-AFLP was carried out using the AFLP ${ }^{\circledR}$ Expression Analysis Kits (LI-COR Biosciences, Lincoln, NE, USA), according to the protocols provided by the manufacturer. Double-strand cDNA was sequentially digested with $\mathrm{TaqI}$ at $65^{\circ} \mathrm{C}$ for 2 hours and with $M s e \mathrm{I}$ at $37^{\circ} \mathrm{C}$ for another 2 hours. After inactivation of the restriction enzymes at $80^{\circ} \mathrm{C}$ for $20 \mathrm{~min}, 9 \mu \mathrm{l}$ of the adapter mixture containing the adapters (TaqI adapters: 5'GCG CGCCGTAGACTGCGTAC 3', 5'CGGTACGCAGTCTACGGCGCGC3', MseI adapters: 5'GGCCGCCGATGAGTCCTGAG3', 5’TACTCAGGACTCATCGGCGG CC3'), $0.4 \mathrm{mM}$ ATP, $10 \mathrm{mM}$ Tris- $\mathrm{HCl} \mathrm{pH}$ 7.5, $10 \mathrm{mM}$ $\mathrm{Mg}(\mathrm{OAc})_{2}, 50 \mathrm{mM} \mathrm{KOAc}$, and 6 Weiss units of T4 DNA ligase (New England Biolabs) were added to the restriction digestion mixture and incubated at $20^{\circ} \mathrm{C}$ for 2 hours.

Subsequently, twenty cycles of pre-amplification were carried out in a $20-\mu \mathrm{l}$ reaction containing $2.5 \mu \mathrm{l}$ of $30-$ fold diluted cDNA template, 100 pmole each of TaqI primer (5'GTAGACTGCGTAC3') and MseI primer (5'GATGAGTCCTGAG3'), $0.25 \mathrm{mM}$ dNTP, $1.5 \mathrm{mM}$ $\mathrm{MgCl}_{2}$, and 5 units of Taq DNA polymerase (Promega, Madison, WI, USA). The PCR thermal cycling consisting of 20 cycles of $94^{\circ} \mathrm{C}$ for $30 \mathrm{sec}, 56^{\circ} \mathrm{C}$ for $1 \mathrm{~min}$, and $72^{\circ} \mathrm{C}$ for 1 min was performed on a GeneAmp PCR system 9600 instrument (Applied Biosystems, Foster city, CA, USA). The amplification products (i.e. the secondary template) were diluted 300 folds and subjected to selective amplification. The reaction contained $6 \mu \mathrm{l}$ of Taq DNA polymerase working mix $(20 \mathrm{mM}$ Tris- $\mathrm{HCl}$ $\mathrm{pH}$ 8.4, $1.5 \mathrm{mM} \mathrm{MgCl}_{2}, 100 \mathrm{mM} \mathrm{KCl}$ and 0.75 unit Taq DNA polymerase), $2 \mu \mathrm{l}$ of the secondary template, $2 \mu \mathrm{l}$ of MseI primer, and $0.5 \mu$ of IRDye 700-labeled TaqI primer. The amplification conditions are as follows: 13 cycles of $94^{\circ} \mathrm{C}$ for $30 \mathrm{sec}, 65^{\circ} \mathrm{C}$ for $30 \mathrm{sec}$ (temperature increment reduction of $0.7^{\circ} \mathrm{C}$ per cycle), and $72^{\circ} \mathrm{C}$ for $1 \mathrm{~min}$, followed by 23 cycles of $94^{\circ} \mathrm{C}$ for $30 \mathrm{sec}, 56^{\circ} \mathrm{C}$ for $30 \mathrm{sec}$, and $72^{\circ} \mathrm{C}$ for $1 \mathrm{~min}$. Samples were denatured at $95^{\circ} \mathrm{C}$ for $5 \mathrm{~min}$ after the addition of stop solution (10 mM NaOH, 95\% formamide, $0.05 \%$ bromophenol blue, $0.05 \%$ xylene cyanol) and separated on a $6.5 \%$ 
$\mathrm{KB}^{\text {Plus }}{ }^{\mathrm{TM}}$ gel. Labeled DNA fragments were visualized and recorded by the automatic DNA Sequencer LI-COR 4300 (LI-COR Biosciences)

\section{Isolating and sequencing the differentially expressed cDNA fragments}

The bands of interest, namely the transcript-derived fragments TDF, were marked on the Odyssey ${ }^{\mathrm{TM}}$ Scanner (LI-COR Biosciences), cut out with a sterile razor blade, and soaked in $10 \mu \mathrm{l}$ of TE buffer (10 mM Tris$\mathrm{HCl}$ pH8.0, 1 mM EDTA). Following a series of freezethaw steps, the cDNA fragments were leached out from the gel by centrifugation at the top speed of a microfuge for $20 \mathrm{~min}$ at $4^{\circ} \mathrm{C}$. Re-amplification of the cDNA fragments was carried out under the same conditions of the pre-amplification step. The PCR products were separated on a $5 \%$ polyacrylamide gel and cloned into pGEM ${ }^{\circledR}-\mathrm{T}$ Easy vector (Promega). DNA sequencing was conducted using the Simultaneous Bidirectional Sequencing ( $\mathrm{SBS}^{\text {тм }}$ ) method (LI-COR) on a Global IR ${ }^{2}$ System (LI-COR). DNA sequence homology search within the GenBank ${ }^{\circledR}$ database was performed using BLAST [33].

\section{Semi-quantitative RT-PCR}

First-strand cDNA of RNA prepared from mock- or BaMV-inoculated $N$. benthamiana plants was synthesized with $d(T)_{39}$ primer using SuperScrpt ${ }^{\circledR}$ III reverse transcriptase (Invitrogen, Carlsbad, CA, USA). Four sets of primers were used to confirm the expression profiles of four cDNA fragments identified by cDNA-AFLP, namely ACAG2-1, ACCT8-1, ACCT2-1, and ACCT13. The forward primers are (5'GAACAAAAAAATGGAGTTTTA3'), (5'CGAACTCCCAACTGGCTTTC3'), (5'CTCTGGAAAGGAGAGCAATGTC3'), and (5'GAAC GCTTTGATGAGAATAGAGA3') and the reverse primers (5'GTCATTGCTCCTAATAAGGT3'), (5'CTCC TCCAGAAGCAAATAGTTTC3'), (5'CGAACAAATT GGTGTATCC3'), and (5'CTAACTCAACCGCAGCC TTT3'), respectively. PCR amplifications were performed using Taq DNA polymerase (Promega) with 28 cycles of $94^{\circ} \mathrm{C}$ for $30 \mathrm{sec}, 55^{\circ} \mathrm{C}$ for $30 \mathrm{sec}$, and $72^{\circ} \mathrm{C}$ for $30 \mathrm{sec}$. PCR products were separated on a $5 \%$ polyacrylamide gel and visualized by EtBr staining.

Primer pairs for ACAG1 (forward, 5'GAGAAAATGAAGGAGAAGGCCC3'; reverse, 5'GCTCTGCCTT CTTCAATTGCTTCTT3') and ACAG8 (forward, 5'GAAGGAAGCTGTGAATGTGTCA3'; reverse, 5'TGG TTAAGTTCATACGGAAAGA3') were used to determine the knockdown efficiency of host genes by VIGS (virus-induced gene silencing). The actin primer pair (forward, 5'GTGGTTTCATGAATGCCAGCA3'; reverse
5'GATGAAGATACTCACAGAAAGA3') was used for normalization of RT-PCR data.

\section{Virus-induced gene silencing (VIGS)}

Two transcript-derived fragments (ACAG1 and ACAG8) were first cloned into pGEM-T Easy vector (Promega) and subcloned into the EcoRI site of the pTRV2 vector [28]. The control plasmid pTRV2/mGFP was obtained by subcloning the KpnI-XhoI fragment containing the polyhistidine-tagged mGFP5-coding sequence [34] from pBI-mGFP1 into pTRV2. The pTRV2/ACAG1, pTRV2/ ACAG8 and pTRV2/mGFP constructs were transformed into Agrobacterium tumefaciens C58C1 strain by electroporation.

For agroinfiltration, the $A$. tumefaciens $\mathrm{C} 58 \mathrm{C} 1$ containing pTRV1, pTRV2/mGFP, pTRV2/ACAG1, or pTRV2/ACAG8 was cultured to $\mathrm{OD}_{600}=1$ at $30^{\circ} \mathrm{C}$ and subjected to induction in $150 \mu \mathrm{M}$ acetosyringone and $10 \mathrm{mM} \mathrm{MgCl}_{2}$ for $2 \mathrm{~h}$ at room temperature. Subsequently, the pTRV2/mGFP-, pTRV2/ACAG1- or pTRV2/ACAG8-containing A. tumefaciens C58C1 was mixed with the pTRV1-containing $A$. tumefaciens C58C1 at a $1: 1(\mathrm{v}: \mathrm{v})$ ratio. The $2^{\text {nd }}$ and $3^{\text {rd }}$ true leaves were infiltrated with the mixture at the four-leaf stage (seedlings with two cotyledons and two leaves). BaMV virion RNA $(1 \mu \mathrm{g})$ was inoculated onto the $7^{\text {th }}$ leaf when the plants were mature. Total RNAs and proteins were extracted from the leaves on $5 \mathrm{dpi}$ for subsequent studies.

\section{Protein detection}

Total proteins of the leaves were extracted in $1 \mathrm{x}$ Laemmli buffer (2.5 mM Tris- $\mathrm{HCl}, \mathrm{pH} 8.3,250 \mathrm{mM}$ glycine and $0.1 \%$ SDS) and incubated in boiling water for $5 \mathrm{~min}$. Proteins separated by SDS-PAGE were subjected to Western blotting analysis using the polyclonal rabbit anti-BaMV coat protein antibody. The relative levels of the Rubisco large subunit ( $\mathrm{rbcL}$ ) in gels stained with Coomassie Blue were determined and used for the normalization of the Western blotting signals.

\section{Additional material}

\footnotetext{
Additional file 1: Table S1: Transcript-derived fragments identified by CDNA-AFLP analysis and differentially expressed between Mockand Bamboo mosaic virus-inoculated Nicotiana benthamiana plants Table S2: The primer set and their sequence for RT-PCR to examine the knockdown efficiency.

Additional file 2: Figure S1 - Phenotypes of gene-specific knockdown plants generated by the TRV VIGS system. Transcription of ACCA3, ACGT12, or ACAG8 in N. benthamiana plant was introduced by the TRV vector to knock down expression of the corresponding host genes. The Luc plant in which the luciferase gene was introduced was included as a negative control. Figure S2 - RT-PCR analysis of host gene expression in knockdown plants. The knockdown plants as indicated above each lane were inoculated with viral RNA. The GFP plant was
} 
included as the negative control. The RNA extracts derived from the leaves inoculated with viral RNA were harvested on 5 dpi and subjected to specific primers indicated on the left for semi-quantitative RT-PCR. RTPCR data was normalized to the levels of actin.

\section{Acknowledgements}

We are grateful to Ms Lin-Ling Shang-Guan, Ms Hui-Ting Chen, Mr. MengHsuen Chiu, Mr. Jui-Cheng Yu, and Mr. Yu-Shun Kao for their contributions on some of the experiments. We are also grateful to Dr. Pei-Yu Lee of Institute of Medical Biotechnology, Central Taiwan University of Sciences and Technology for editorial help. This work was supported by grants from the National Science Council through research grants NSC 96-2752-B-005-012PAE and NSC 97-2752-B-005-004-PAE.

\section{Author details}

'Graduate Institute of Biotechnology, National Chung Hsing University, Taichung, 40227, Taiwan. ${ }^{2}$ Graduate Institute of Medical Laboratory Science and Biotechnology, China Medical University, Taichung, 404, Taiwan.

\section{Authors' contributions}

SFC prepared CDNAs for AFLP analysis, cloned the isolated CDNA fragments, conducted the VIGS experiments, YPH performed the cloning and sequencing of the CDNAs derived from CDNA-AFLP, ZRW conducted inoculation and harvesting of $\mathrm{N}$. benthamiana plants with $\mathrm{BaMV}, \mathrm{CCH}$ undertook bioinformatics analysis of sequence data and participated in the discussion, $\mathrm{YHH}$ and $\mathrm{CHT}$ were project supervisors, participated in the discussion of all experiments of the project and preparation of the manuscript.

All authors read and approved the final manuscript.

Received: 25 November 2009 Accepted: 27 December 2010 Published: 27 December 2010

\section{References}

1. Ahlquist P, Noueiry AO, Lee WM, Kushner DB, Dye BT: Host factors in positive-strand RNA virus genome replication. J Virol 2003, 77(15):8181-8186.

2. Cohn J, Sessa G, Martin GB: Innate immunity in plants. Curr Opin Immunol 2001, 13(1):55-62.

3. Boller T, Felix G: A renaissance of elicitors: perception of microbeassociated molecular patterns and danger signals by pattern-recognition receptors. Annu Rev Plant Biol 2009, 60:379-406.

4. Hills GJ, Plaskitt KA, Young ND, Dunigan DD, Watts JW, Wilson TM, Zaitlin M: Immunogold localization of the intracellular sites of structural and nonstructural tobacco mosaic virus proteins. Virology 1987, 161(2):488-496.

5. Voinnet O: RNA silencing as a plant immune system against viruses. Trends Genet 2001, 17(8):449-459.

6. Crawford KM, Zambryski PC: Plasmodesmata signaling: many roles, sophisticated statutes. Curr Opin Plant Biol 1999, 2(5):382-387.

7. Crawford KM, Zambryski PC: Phloem transport: Are you chaperoned? Curr Biol 1999, 9(8):R281-285.

8. Lazarowitz SG, Beachy RN: Viral movement proteins as probes for intracellular and intercellular trafficking in plants. Plant Cell 1999, 11(4):535-548.

9. Lucas WJ, Wolf S: Connections between virus movement, macromolecular signaling and assimilate allocation. Curr Opin Plant Biol 1999, 2(3):192-197.

10. Gutierrez C: DNA replication and cell cycle in plants: learning from geminiviruses. EMBO J 2000, 19(5):792-799.

11. Kim HK, Jones JDG: Responses to Plant Pathogens. In Biochemistry \& Molecular Biology of Plants. Edited by: Buchanan B, Gruissem W, Jones R. American Society of Plant Physiologists; 2000:1102-1156.

12. Baker B, Zambryski P, Staskawicz B, Dinesh-Kumar SP: Signaling in plantmicrobe interactions. Science 1997, 276(5313):726-733.

13. Cooper B: Collateral gene expression changes induced by distinct plant viruses during the hypersensitive resistance reaction in Chenopodium amaranticolor. Plant J 2001, 26(3):339-349.
14. Lin NS, Lin BY, Lo NW, Hu CC, Chow TY, Hsu YH: Nucleotide sequence of the genomic RNA of Bamboo mosaic potexvirus. J Gen Virol 1994, 75(9):2513-2518

15. Li Yl, Chen YJ, Hsu YH, Meng M: Characterization of the AdoMetdependent guanylyltransferase activity that is associated with the $\mathrm{N}$ terminus of Bamboo mosaic virus replicase. J Virol 2001, 75(2):782-788.

16. Huang YL, Han YT, Chang YT, Hsu YH, Meng M: Critical residues for GTP methylation and formation of the covalent m7GMP-enzyme intermediate in the capping enzyme domain of Bamboo mosaic virus. $J$ Virol 2004, 78(3):1271-1280.

17. Huang $Y L$, Hsu YH, Han YT, Meng M: mRNA guanylation catalyzed by the S-adenosylmethionine-dependent guanylyltransferase of Bamboo mosaic virus. J Biol Chem 2005, 280(13):13153-13162.

18. Han YT, Hsu YH, Lo CW, Meng M: Identification and functional characterization of regions that can be crosslinked to RNA in the helicase-like domain of BaMV replicase. Virology 2009, 389(1-2):34-44.

19. Han YT, Tsai CS, Chen YC, Lin MK, Hsu YH, Meng M: Mutational analysis of a helicase motif-based RNA 5'-triphosphatase/NTPase from Bamboo mosaic virus. Virology 2007, 367(1):41-50.

20. Li Yl, Cheng YM, Huang YL, Tsai CH, Hsu YH, Meng M: Identification and characterization of the Escherichia coli-expressed RNA-dependent RNA polymerase of bamboo mosaic virus. J Virol 1998, 72(12):10093-10099.

21. Lin MK, Chang BY, Liao JT, Lin NS, Hsu YH: Arg-16 and Arg-21 in the Nterminal region of the triple-gene-block protein 1 of Bamboo mosaic virus are essential for virus movement. J Gen Virol 2004, 85(1):251-259.

22. Lin MK, Hu CC, Lin NS, Chang BY, Hsu YH: Movement of potexviruses requires species-specific interactions among the cognate triple gene block proteins, as revealed by a trans-complementation assay based on the bamboo mosaic virus satellite RNA-mediated expression system. J Gen Virol 2006, 87(5):1357-1367.

23. Lin JW, Ding MP, Hsu YH, Tsai CH: Chloroplast phosphoglycerate kinase, a gluconeogenetic enzyme, is required for efficient accumulation of Bamboo mosaic virus. Nucleic Acids Res 2007, 35(2):424-432.

24. Cheng CW, Hsiao YY, Wu HC, Chuang CM, Chen JS, Tsai CH, Hsu YH, Wu YC, Lee CC, Meng M: Suppression of Bamboo mosaic virus accumulation by a putative methyltransferase in Nicotiana benthamiana. J Virol 2009, 83(11):5796-5805.

25. Bachem CW, van der Hoeven RS, de Bruijn SM, Vreugdenhil D, Zabeau M, Visser RG: Visualization of differential gene expression using a novel method of RNA fingerprinting based on AFLP: analysis of gene expression during potato tuber development. Plant J 1996, 9(5):745-753.

26. Ditt RF, Nester EW, Comai L: Plant gene expression response to Agrobacterium tumefaciens. Proc Natl Acad Sci USA 2001, 98(19):10954-10959.

27. Vos P, Hogers R, Bleeker M, Reijans M, van de Lee T, Hornes M, Frijters A, Pot J, Peleman J, Kuiper M, et al: AFLP: a new technique for DNA fingerprinting. Nucleic Acids Res 1995, 23(21):4407-4414.

28. Ruiz MT, Voinnet O, Baulcombe DC: Initiation and maintenance of virusinduced gene silencing. Plant Cell 1998, 10(6):937-946.

29. Hiriart JB, Aro EM, Lehto K: Dynamics of the VIGS-mediated chimeric silencing of the Nicotiana benthamiana ChIH gene and of the Tobacco mosaic virus vector. Mol Plant Microbe Interact 2003, 16(2):99-106.

30. Ramonell KM, Somerville S: The genomics parade of defense responses: to infinity and beyond. Curr Opin Plant Biol 2002, 5(4):291-294.

31. Ratcliff F, Martin-Hernandez AM, Baulcombe DC: Technical Advance. Tobacco rattle virus as a vector for analysis of gene function by silencing. Plant J 2001, 25(2):237-245.

32. Jackson PK, Eldridge AG, Freed E, Furstenthal L, Hsu JY, Kaiser BK, Reimann JD: The lore of the RINGs: substrate recognition and catalysis by ubiquitin ligases. Trends Cell Biol 2000, 10(10):429-439.

33. Altschul SF, Madden TL, Schaffer AA, Zhang J, Zhang Z, Miller W, Lipman DJ: Gapped BLAST and PSI-BLAST: a new generation of protein database search programs. Nucleic Acids Res 1997, 25(17):3389-3402.

34. Siemering KR, Golbik R, Sever R, Haseloff J: Mutations that suppress the thermosensitivity of green fluorescent protein. Curr Biol 1996, 6(12):1653-1663.

doi:10.1186/1471-2229-10-286

Cite this article as: Cheng et al:: Identification of differentially expressed genes induced by Bamboo mosaic virus infection in Nicotiana benthamiana by CDNA-amplified fragment length polymorphism. BMC Plant Biology 2010 10:286. 